\title{
Clinical Study \\ Effects of Telmisartan with Hydrochlorothiazide versus Valsartan with Hydrochlorothiazide in Patients with Moderate-to-Severe Hypertension
}

\author{
Ravi Marfatia, ${ }^{1}$ William B. White, ${ }^{1}$ and Helmut Schumacher ${ }^{2}$ \\ ${ }^{1}$ Division of Hypertension and Clinical Pharmacology, Pat and Jim Calhoun Cardiology Center, \\ University of Connecticut School of Medicine, Farmington, CT 06030, USA \\ ${ }^{2}$ Medical Data Services Department, Boehringer Ingelheim GmbH, Binger Straße 173, 5216 Ingelheim am Rhein, Germany
}

Correspondence should be addressed to William B. White, wwhite@nso1.uchc.edu

Received 29 February 2012; Accepted 21 May 2012

Academic Editor: Thomas Unger

Copyright (C) 2012 Ravi Marfatia et al. This is an open access article distributed under the Creative Commons Attribution License, which permits unrestricted use, distribution, and reproduction in any medium, provided the original work is properly cited.

\begin{abstract}
Combination therapy is recommended for patients with blood pressure (BP) significantly above goal by recent consensus guidelines around the globe. The use of angiotensin II receptor blockers (ARBs) alone or in combination with a thiazide diuretic is a preferred treatment strategy due to both efficacy and safety considerations. However, there are few data known about the benefits of ARB-diuretic combination therapy in patients with moderate-to-severe hypertension. We performed a subanalysis from two large clinical trials that compared the antihypertensive effects of telmisartan $80 \mathrm{mg}$ versus valsartan $160 \mathrm{mg}$, both combined with hydrochlorothiazide (HCTZ) $25 \mathrm{mg}$ in a subpopulation of 725 patients with moderate-to-severe hypertension (systolic BP $\mathrm{SBP} \geq 160 \mathrm{~mm} \mathrm{Hg}$ ). Treatment with telmisartan-HCTZ induced significantly greater reductions in $\mathrm{BP}(-31.1 /-18.3 \mathrm{~mm} \mathrm{Hg})$ than valsartan-HCTZ $(-28.4 /-16.3 \mathrm{~mm} \mathrm{Hg}$; SBP $P=0.0265$, diastolic BP $P=0.0041)$. More patients receiving the telmisartan combination achieved a BP goal $<140 / 90 \mathrm{~mm} \mathrm{Hg}$ than those receiving valsartan-HCTZ. There were similar safety and tolerability data for the two active treatment groups. These findings support the use of longer-acting ARBs combined with higher doses of thiazide diuretic to improve BP control in patients with moderate-to-severe hypertension.
\end{abstract}

\section{Introduction}

The angiotensin II receptor blockers (ARBs) are effective antihypertensive agents with tolerability profiles similar to placebo [1-4]. The use of ARBs and/or angiotensin converting enzyme (ACE) inhibitors, alone or in combination with a calcium channel blocker or with a thiazide diuretic, has become the cornerstone of hypertension management $[2,5$, 6]. A series of landmark clinical trials have demonstrated that $\mathrm{ARBs}$ reduce cardiovascular $(\mathrm{CV})$ morbidity and mortality in a variety of types of hypertensive patients [7-13].

In seeking to improve blood pressure (BP) control, use of hydrochlorothiazide (HCTZ) at $25 \mathrm{mg}$ rather than $12.5 \mathrm{mg}$ in combination with ARBs and ACE inhibitors is recognized as an effective and well-tolerated strategy $[1,2$, 14]. Two independent and identically designed trials were previously conducted to evaluate the benefits and safety of two single-pill combination (SPC) therapies: telmisartan $80 \mathrm{mg}$ plus HCTZ $25 \mathrm{mg}$ (T80/H25) and valsartan $160 \mathrm{mg}$ plus HCTZ $25 \mathrm{mg}(\mathrm{V} 160 / \mathrm{H} 25)$ in patients with stages 1 and 2 hypertension $[15,16]$. A pooled analysis of these two studies provided support for the use of ARBs with this higher $25 \mathrm{mg}$ dose of thiazide diuretic; furthermore, the analysis demonstrated that $\mathrm{T} 80 / \mathrm{H} 25$ resulted in greater reductions in clinic BP than V160/H25 [17].

As patients with moderate-to-severe hypertension have proportionally increased risk for CV morbidity and mortality, it is important to assess the magnitude of BP lowering with high doses of combination therapy in these hypertensive patients. In our pooled analysis of T80/H25 versus V160/H25, a substantial proportion of patients participating had stage (or grade) 2 hypertension [17]. The aim of the present analysis was to evaluate the efficacy and tolerability of both combination antihypertensive treatments in those 
patients who had moderate-to-severe hypertension, specifically defined as systolic BP (SBP) $\geq 160 \mathrm{~mm} \mathrm{Hg}$ at baseline.

\section{Methods}

2.1. Study Design. The two studies had identical designs and were multicenter, double-blind, double-dummy, randomized, parallel-group studies that compared the efficacy and safety of T80/H25 versus V160/H25 or placebo. The methods and results for the entire population have been reported elsewhere [15-17].

The aim of the two trials was to determine whether T80/H25 mg administered once daily (o.d.) was superior to placebo administered o.d. and noninferior or superior to $\mathrm{V} 160 / \mathrm{H} 25 \mathrm{mg}$ o.d. for the control of BP measured in the clinic following 8 weeks of treatment. A 3- to 4week run-in period included a 1-week washout for patients currently receiving antihypertensive therapy, followed by a 2- to 3-week single-blind placebo period to establish baseline BP values. Eligible patients were then randomized to double-blind monotherapy treatment of telmisartan $80 \mathrm{mg}$, valsartan $160 \mathrm{mg}$, or placebo in a ratio of $4: 4: 1$, respectively. After 2 weeks, all patients were uptitrated to combination treatment with $\mathrm{T} 80 / \mathrm{H} 25$, V160/H25, or placebo, depending on their initial randomized treatment arm.

2.2. Patient Population. Men and women with average seated diastolic BP (DBP) of $\geq 95 \mathrm{~mm} \mathrm{Hg}$ to $\leq 120 \mathrm{~mm} \mathrm{Hg}$ at the end of the single-blind placebo treatment period were eligible for inclusion in both studies. The group of patients included in this current subanalysis had moderateto-severe hypertension, defined as an average seated SBP of $\geq 160 \mathrm{~mm} \mathrm{Hg}$ at baseline. Patients with stroke or myocardial infarction (MI) within the past 6 months, congestive heart failure, known or suspected secondary hypertension, poorly controlled diabetes mellitus, or chronic kidney failure were excluded from the studies.

2.3. Measurements of Efficacy and Safety Parameters. Clinic $\mathrm{BP}$ was measured by study personnel using either a mercury column or aneroid manometry in the seated position. Three replicate measurements were averaged for analysis. Pulse rate was measured once in conjunction with BP at each study visit. Safety was assessed by evaluation of adverse events and vital signs at each study visit. All reported adverse events were categorized by body system and preferred term according to the Medical Dictionary for Regulatory Activities.

2.4. Statistical Analysis. Demographic, efficacy, and safety data for the subpopulation of moderate-to-severe hypertensive patients (i.e., patients with a baseline SBP of $\geq 160 \mathrm{~mm} \mathrm{Hg}$ ) were merged into a common database for analysis as described previously for the entire pooled population [17]. The primary endpoints for assessing efficacy were the changes from baseline to the end-of-study visit in clinic SBP and DBP, measured at the post dosing trough of study medication (23-26h). In the case of patients withdrawing from the study prior to the completion of the 8-week
TABLE 1: Baseline characteristics.

\begin{tabular}{lccc}
\hline & T80/H25 & V160/H25 & Placebo \\
\hline$N$ & 328 & 317 & 80 \\
Age, years (SD) & $57.0(10.7)$ & $56.0(9.7)$ & $56.4(10.6)$ \\
Age group, $N(\%)$ & & & \\
$\quad<65$ years & $255(77.7)$ & $261(82.3)$ & $63(78.8)$ \\
$\quad \geq 65$ years & $73(22.3)$ & $56(17.7)$ & $17(21.3)$ \\
Gender, $N$ (\%) & & & \\
$\quad$ Male & $181(55.2)$ & $176(55.5)$ & $43(53.8)$ \\
$\quad$ Female & $147(44.8)$ & $141(44.5)$ & $37(46.3)$ \\
Race, $N$ (\%) & & & \\
$\quad$ Non-Black & $241(73.5)$ & $230(72.6)$ & $57(71.3)$ \\
$\quad$ Black & $87(26.5)$ & $87(27.4)$ & $23(28.8)$ \\
BMI, kg/m ${ }^{2}$ (SD) & $31.4(6.1)$ & $31.8(6.8)$ & $31.5(6.2)$ \\
SBP, mm Hg (SD) & $167.6(5.4)$ & $168.3(5.9)$ & $167.1(5.8)$ \\
DBP, mm Hg (SD) & $103.2(4.4)$ & $103.4(4.8)$ & $103.3(4.0)$ \\
Pulse rate, beats/min (SD) & $75.7(9.9)$ & $75.0(9.4)$ & $74.5(8.8)$ \\
\hline
\end{tabular}

BMI: body mass index; DBP: diastolic blood pressure; SBP: systolic blood pressure; SD: standard deviation; T80/H25: telmisartan $80 \mathrm{mg} /$ hydrochlorothiazide $25 \mathrm{mg}$; V160/H25: valsartan $160 \mathrm{mg}$ / hydrochlorothiazide $25 \mathrm{mg}$.

treatment period, last-observation-carried-forward (LOCF) principles were utilized in those patients who had at least one set of BP measurements following titration to combination therapy. LOCF could only be used in those subjects who entered into the combination phase of the double-blind treatment period.

All analyses performed in the subpopulation of moderate-to-severe hypertensive patients were performed as post hoc assessments. Results of treatment comparisons are presented as two-sided $P$ values. Mean changes in seated trough clinic BP per treatment group were adjusted for effects of baseline, study, gender, and race as previously described [17]. The impact of age, gender, and race on changes from baseline in SBP and DBP is also described. The probability of achieving BP goal (DBP $<90 \mathrm{~mm} \mathrm{Hg}$, $\mathrm{SBP}<140 \mathrm{~mm} \mathrm{Hg}$ ) depending on baseline BP and treatment was calculated using logistic regression.

\section{Results}

3.1. Patient Enrolment and Disposition. A total of 2121 patients were randomized and received treatment $(\mathrm{T} 80 / \mathrm{H} 25$, $n=942 ; \mathrm{V} 160 / \mathrm{H} 25, n=952$; placebo, $n=227$ ) across the two studies. Of these, 725 patients had moderate-tosevere hypertension at baseline $(\mathrm{SBP} \geq 160 \mathrm{~mm} \mathrm{Hg})$ and were included in this subanalysis (T80/H25, $n=328$; V160/H25, $n=317$; placebo, $n=80$ ).

3.2. Baseline Characteristics of Study Population. Baseline characteristics of the subpopulation of patients with SBP $\geq 160 \mathrm{~mm} \mathrm{Hg}$ are shown in Table 1. There were no differences in baseline characteristics observed among the three treatment arms. Mean age of the total population of patients with moderate-to-severe hypertension was 56.5, years and 
TABLE 2: Mean seated clinic trough BP and changes from baseline by treatment group.

\begin{tabular}{|c|c|c|c|}
\hline & $\mathrm{T} 80 / \mathrm{H} 25(n=328)$ & $\mathrm{V} 160 / \mathrm{H} 25(n=317)$ & Placebo $(n=80)$ \\
\hline \multicolumn{4}{|l|}{ SBP, $\mathrm{mm} \mathrm{Hg}$} \\
\hline Baseline (SD) & $167.6(5.4)$ & $168.3(5.8)$ & $167.1(5.9)$ \\
\hline End of study (SD) & $136.6(15.3)$ & $139.75(16.4)$ & $160.2(14.9)$ \\
\hline Change from baseline (SD) & $-31.1(15.1)$ & $-28.6(15.9)$ & $-7.0(14.3)$ \\
\hline Adjusted $^{\text {a }}$ change from baseline (SE) & $-31.1(0.9)$ & $-28.4(0.9)$ & $-7.3(1.7)$ \\
\hline Comparison to $\mathrm{T} 80 / \mathrm{H} 25$ (95\% CI) & & $\begin{array}{c}-2.7(-5.1,-0.3) \\
P=0.0265\end{array}$ & $\begin{array}{c}-23.8(-27.5,-20.0) \\
P<0.0001\end{array}$ \\
\hline \multicolumn{4}{|l|}{ DBP, $\mathrm{mm} \mathrm{Hg}$} \\
\hline Baseline (SD) & $103.2(4.4)$ & $103.4(4.8)$ & $103.4(4.1)$ \\
\hline End of study (SD) & $85.1(9.4)$ & $87.3(10.4)$ & $98.3(10.1)$ \\
\hline Change from baseline (SD) & $-18.1(8.7)$ & $-16.1(9.3)$ & $-5.0(9.5)$ \\
\hline Adjusted $^{\text {a }}$ change from baseline (SE) & $-18.3(0.52)$ & $-16.3(0.5)$ & $-5.3(1.0)$ \\
\hline Comparison to T80/H25 (95\% CI) & & $\begin{array}{c}-2.0(-3.4,-0.6) \\
P=0.0041\end{array}$ & $\begin{array}{c}-13.0(-15.2,-10.8) \\
P<0.0001\end{array}$ \\
\hline
\end{tabular}

BP: blood pressure; CI: confidence interval; DBP: diastolic blood pressure; SBP: systolic blood pressure; SD: standard deviation; SE: standard error; T80/H25: telmisartan $80 \mathrm{mg}$ /hydrochlorothiazide $25 \mathrm{mg}$; V160/H25: valsartan $160 \mathrm{mg}$ /hydrochlorothiazide $25 \mathrm{mg}$.

${ }^{a}$ Adjusted for effects of baseline, study, gender, and race.

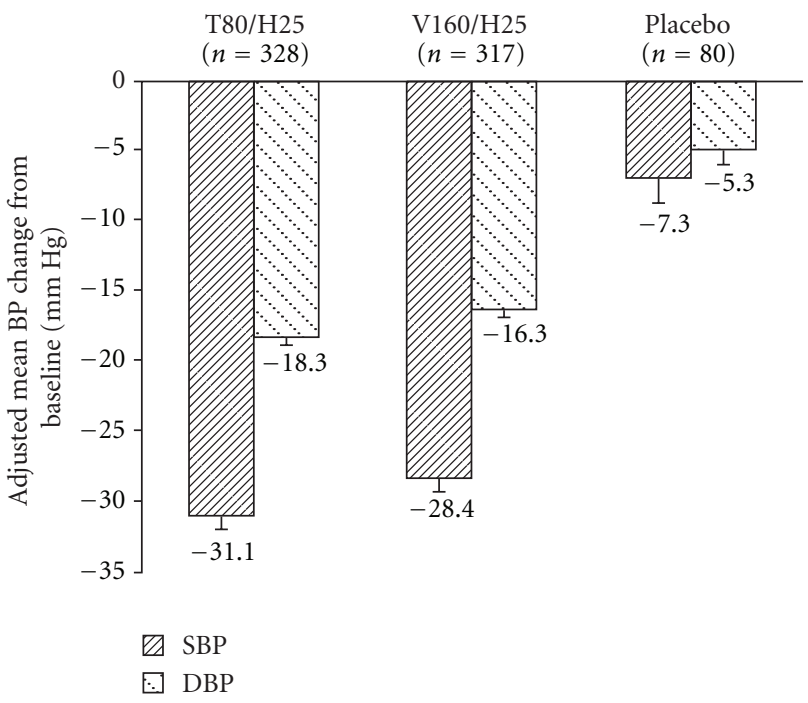

T80/H25 versus V160/H25: $P=0.0265$ for SBP and $P=0.0041$ for DBP. T80/H25 versus placebo: $P<0.001$ for both SBP and DBP.

Figure 1: Change from baseline in SBP and DBP by treatment group. (T80/H25, telmisartan $80 \mathrm{mg} /$ hydrochlorothiazide $25 \mathrm{mg}$ : V160/H25, valsartan $160 \mathrm{mg} /$ hydrochlorothiazide $25 \mathrm{mg}$ ).

mean seated baseline BP was 167.7/103.3 mm Hg. Mean body mass index was $31.6 \mathrm{~kg} / \mathrm{m}^{2}$, and the majority $(79.9 \%)$ of patients were aged $<65$ years. Most of the patients were male (55.2\%) and non-Black (72.8\%).

3.3. Changes in Clinic Trough (Approximately 24h AfterDose) BP. The effects of the treatment on mean seated trough clinic BP among the subpopulation of patients with moderate-to-severe hypertension are illustrated in Figure 1 and tabulated in Table 2. BP was substantially lowered in both active treatment groups compared with placebo. Reduction in mean seated trough clinic BP with T80/H25 $(-31.1 /-18.3 \mathrm{~mm} \mathrm{Hg})$ was significantly greater than that with placebo $(-7.3 /-5.3 \mathrm{~mm} \mathrm{Hg} ; P<0.0001$ for both SBP and DBP). Treatment with V160/H25 induced reductions in mean seated trough clinic BP of $-28.4 /-16.3 \mathrm{~mm} \mathrm{Hg}$. Treatment with $\mathrm{T} 80 / \mathrm{H} 25$ was associated with a significantly greater mean reduction in BP compared with V160/H25 for both SBP (adjusted mean difference $-2.7 \mathrm{~mm} \mathrm{Hg} ; 95 \%$ confidence interval (CI), $-5.1,-0.3 ; P=0.0265)$ and DBP (adjusted mean difference $-2.0 \mathrm{~mm} \mathrm{Hg}$; 95\% CI, -3.4, $-0.6 ; P=0.0041)$. The probability of achieving $\mathrm{BP}$ goal $(<140 / 90 \mathrm{~mm} \mathrm{Hg}$ ) was dependent on baseline SBP and differed between treatment arms (Figure 2). Averaged over the complete range of baseline SBP, the probability was 4\% with placebo, 52\% with $\mathrm{T} 80 / \mathrm{H} 25$, and $43 \%$ with $\mathrm{V} 160 / \mathrm{H} 25$ (odds ratio comparing T80/H25 and V160/H25 was 1.47; 95\% CI, 1.06, 2.02, $P=0.0194)$.

3.4. Impact of Age, Gender, and Race on Changes in BP. The impact of age ( $<65$ and $\geq 65$ years) on reductions in $\mathrm{BP}$ is shown in Figure $3(\mathrm{a})$. In patients aged $<65$ years, T80/H25 resulted in significantly greater $\mathrm{BP}$ reductions from baseline (adjusted mean SBP/DBP change -31.6/ $-18.0 \mathrm{~mm} \mathrm{Hg}$ ) than $\mathrm{V} 160 / \mathrm{H} 25$ (adjusted mean SBP/DBP change $-28.0 /-15.8 \mathrm{~mm} \mathrm{Hg} ; P=0.0063$ for difference in SBP and $P=0.0041$ for DBP). No significant differences in $\mathrm{BP}$ change were observed between the active treatment groups in patients aged $\geq 65$ years $(-30.3 /-19.4 \mathrm{~mm} \mathrm{Hg}$ for T80/H25 versus $-30.2 /-18.6 \mathrm{~mm} \mathrm{Hg}$ for V160/H25).

The impact of gender on reductions in $\mathrm{BP}$ is shown in Figure 3(b). In male patients, T80/H25 resulted in significantly greater BP reductions from baseline (adjusted mean SBP/DBP change $-29.3 /-17.6 \mathrm{~mm} \mathrm{Hg}$ ) than V160/ 


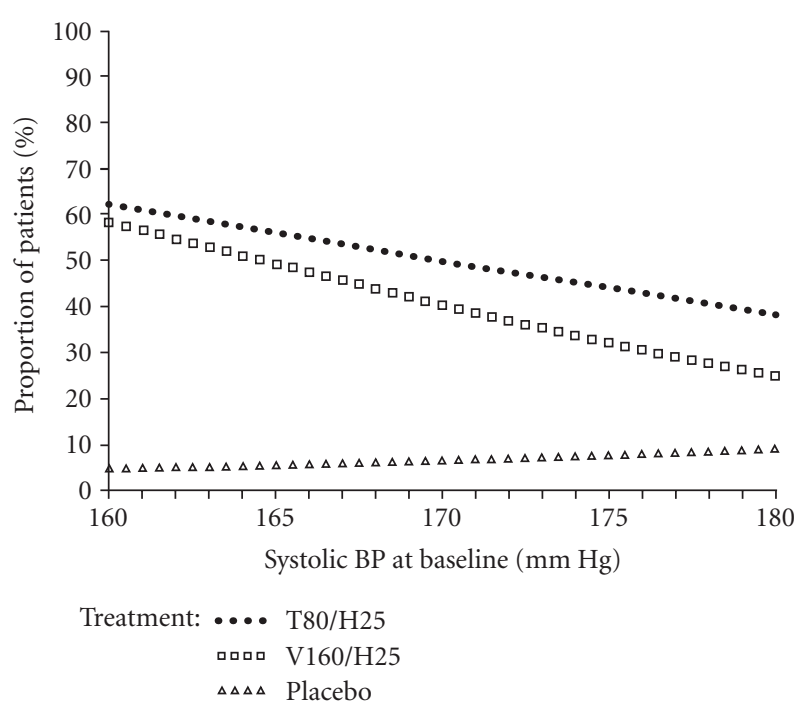

FIgURE 2: Proportion of patients achieving BP goal $(<140$ $190 \mathrm{~mm} \mathrm{Hg}$ ), per treatment group, according to SBP at baseline (results from a logistic regression model allowing for treatment-by-baseline SBP interaction). T80/H25: telmisartan $80 \mathrm{mg}$ /hydrochlorothiazide $25 \mathrm{mg}$. V160/H25:valsartan $160 \mathrm{mg} /$ hydrochlorothiazide $25 \mathrm{mg}$.

H25 (adjusted mean SBP/DBP change -25.6/-14.5 mm Hg; $P=0.0221$ for difference in SBP and $P=0.0016$ for DBP). No significant differences in BP change were observed between the active treatment groups in female patients $(-32.8 /-18.9 \mathrm{~mm} \mathrm{Hg}$ for $\mathrm{T} 80 / \mathrm{H} 25$ versus $-31.5 /-18.2$ $\mathrm{mmHg}$ for $\mathrm{V} 160 / \mathrm{H} 25)$. Greater changes from baseline in SBP and DBP were seen in female patients compared with males across the study, and this gender difference was consistent across the three treatment groups.

The impact of race (non-Black and Black) on changes in BP is shown in Figure 3(c). Among non-Black patients, T80/H25 resulted in significantly greater DBP reductions from baseline (adjusted mean DBP change $-18.3 \mathrm{~mm} \mathrm{Hg}$ ) than V160/H25 (adjusted mean DBP change $-16.5 \mathrm{~mm} \mathrm{Hg}$; $P=0.0229$ ). No significant differences in SBP change were observed between the active treatment groups in non-Black patients $(-31.5 \mathrm{~mm} \mathrm{Hg}$ for $\mathrm{T} 80 / \mathrm{H} 25$ versus $-29.5 \mathrm{~mm} \mathrm{Hg}$ for V160/H25). Among Black patients, there were no significant differences in BP change between the active treatment groups (adjusted mean SBP/DBP change -31.3/-18.3 mm Hg for T80/H25 versus -26.6/-15.6 mm Hg for V160/H25).

3.5. Adverse Events. Of the patients randomized to the study who received at least one dose of study medication and were within the subpopulation of patients with moderateto-severe hypertension ( $n=751), 204(27.2 \%)$ had at least one adverse event: $94(27.9 \%)$ in the T80/H25 arm, 73 (22.3\%) in the V160/H25 arm, and 37 (42.5\%) in the placebo arm. Three patients in the $\mathrm{T} 80 / \mathrm{H} 25$ arm $(0.9 \%)$ experienced serious adverse events, compared with one $(0.3 \%)$ in the $\mathrm{V} 160 / \mathrm{H} 25$ arm and none in the placebo arm. None of the patients died. The rate and type of adverse events reported among this subpopulation of patients with moderate-tosevere hypertension were similar to those previously reported for the entire study population [15-17]. The most common adverse events (occurring in $>2 \%$ of patients with moderateto-severe hypertension) are provided in Table 3.

\section{Discussion}

This new analysis of data in the moderate-to-severe hypertensive patients from our two identically designed trials has shown that treatment with T80/H25 lowered SBP and DBP to a significantly greater extent than treatment with V160/H25. As expected, both active treatments lowered BP to a significantly greater extent than placebo. These data build on earlier studies that demonstrated additive and dose-proportionate decreases in BP with telmisartan/HCTZ combinations, and which highlight that the greatest reductions in $\mathrm{BP}$ are achieved in patients with the highest pretreatment BP [3].

Our analysis shows that large reductions from baseline in $\mathrm{BP}$ in those patients whose BP is substantially above clinical targets can be achieved with the combination of an ARB and higher-dose diuretic SPC therapies. After 8 weeks of active treatment, a final mean SBP/DBP $<140 / 90 \mathrm{~mm} \mathrm{Hg}$ occurred in approximately half of the patients with moderate-tosevere hypertension, representing a clinically important achievement in this high-risk patient group. Furthermore, this analysis showed that different ARBs within the SPC therapy had an impact on BP outcomes and targets. Treatment with T80/H25 was significantly more effective than V160/H25 in terms of the proportion of patients who achieved a BP goal of $<140 / 90 \mathrm{~mm} \mathrm{Hg}$.

The results of the analysis herein are comparable to previous studies that have assessed the dose response to valsartan in combination with HCTZ. For example, in a randomized controlled trial reported by Benz et al. [18], V160/H25 mg was shown to lower BP by $22 / 15$ $\mathrm{mm} \mathrm{Hg}$ following 8 weeks of treatment, as compared with V160/H12.5 mg, which lowered BP by $18 / 14 \mathrm{~mm} \mathrm{Hg.} \mathrm{A}$ study by Trenkwalder and colleagues also demonstrated that patients not controlled on V160/H12.5 mg could achieve an additional $8.4 / 8.3 \mathrm{~mm} \mathrm{Hg}$ reduction in $\mathrm{BP}$ when the diuretic dose was increased to $25 \mathrm{mg}$ [19]. These BP-lowering results are similar to those reported for the overall population of patients pooled from our two studies (V160/H25 lowered BP by $22.3 / 16.8 \mathrm{~mm} \mathrm{Hg}$ ) [17] and to the reductions reported in the current analysis (Figure 1; Table 1), in which V160/H25 lowered BP by $28.4 / 16.3 \mathrm{~mm} \mathrm{Hg}$ and T80/H25 lowered BP by $31.1 / 18.3 \mathrm{~mm} \mathrm{Hg}$ at Week 8 in patients with moderate-tosevere hypertension.

In previous studies comparing telmisartan with valsartan as monotherapy in similar doses, telmisartan was shown to induce more sustained BP control, with both greater $24 \mathrm{~h} \mathrm{BP}$ reductions and significantly greater reductions in $\mathrm{BP}$ during the last $6 \mathrm{~h}$ of the dosing period than valsartan $[20,21]$. This may be partly explained by the pharmacokinetic profile of telmisartan, which has a longer half-life $(24 \mathrm{~h})$ compared with valsartan (7 h) $[22,23]$.

In the studies and analysis reported here, despite the potential for "equalizing" the BP-reducing effects of these 

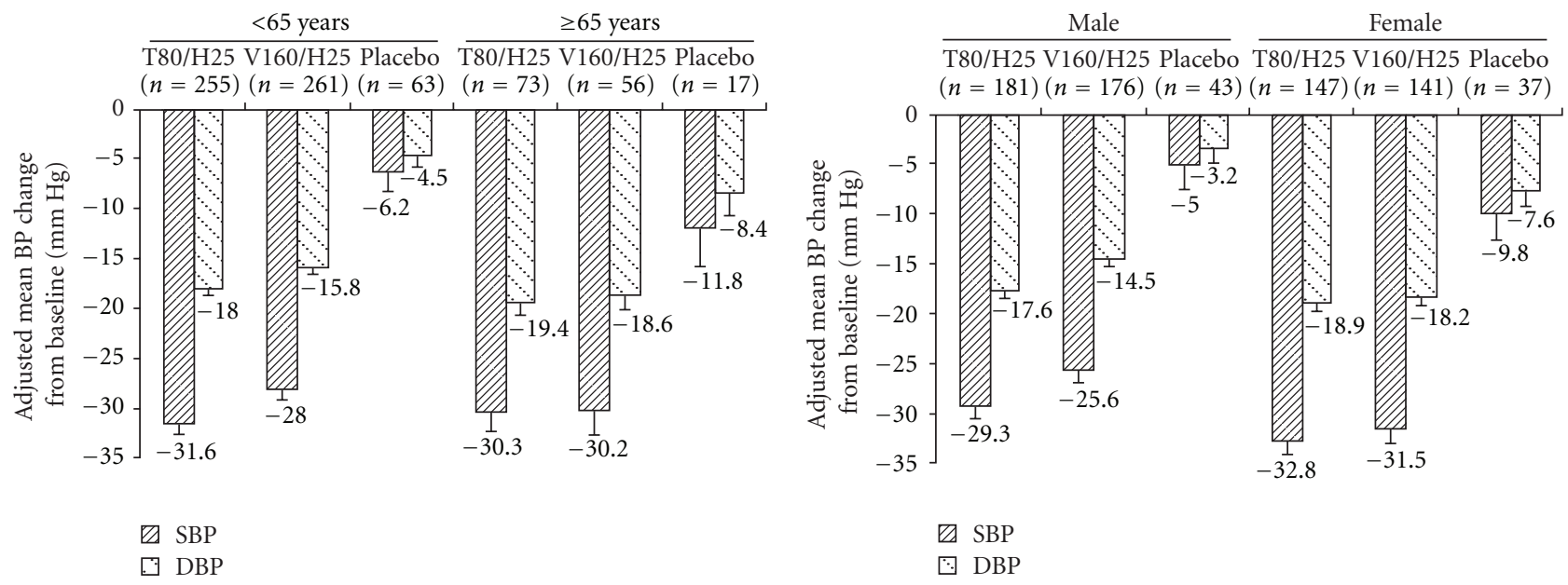

$<65$ years

T80/H25 versus V160/H25: $P=0.0063$ for SBP and $P=0.0041$ for DBP. T80/H25 versus placebo: $P<0.0001$ for both SBP and DBP.

$\geq 65$ years

T80/H25 versus V160/H25: $P=0.9629$ for SBP and $P=0.6431$ for DBP.

T80/H25 versus placebo: $P<0.0001$ for both SBP and DBP.

(a)

Male

T80/H25 versus V160/H25: $P=0.0221$ for SBP and $P=0.0016$ for DBP. T80/H25 versus placebo: $P<0.0001$ for both SBP and DBP.

Female

T80/H25 versus V160/H25: $P=0.4818$ for SBP and $P=0.4664$ for DBP.

T80/H25 versus placebo: $P<0.0001$ for both SBP and DBP.

(b)

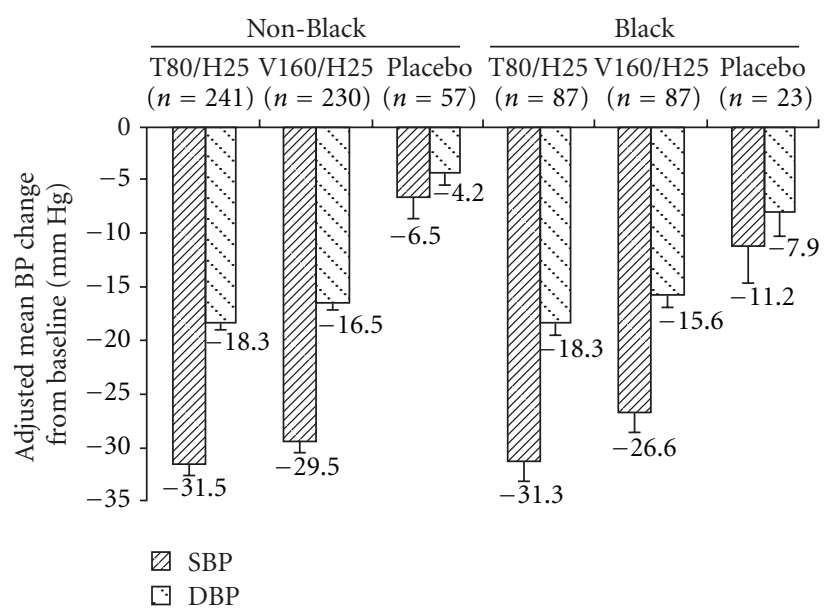

Non-Black

T80/H25 versus V160/H25: $P=0.1482$ for SBP and $P=0.0229$ for DBP.

T80/H25 versus placebo: $P<0.0001$ for both SBP and DBP.

Black

T80/H25 versus V160/H25: $P=0.0586$ for SBP and $P=0.0803$ for DBP.

T80/H25 versus placebo: $P<0.0001$ for both SBP and DBP.

(c)

Figure 3: Impact of age (a), gender (b), and race (c) on changes from baseline in BP by treatment group. T80/H25, telmisartan $80 \mathrm{mg}$ /hydrochlorothiazide $25 \mathrm{mg}$ : V160/H25, valsartan $160 \mathrm{mg}$ /hydrochlorothiazide $25 \mathrm{mg}$.

two ARBs by combining treatments with $25 \mathrm{mg}$ thiazide diuretic, differences between telmisartan and valsartan were preserved, with significantly greater reductions in $\mathrm{BP}$ noted in the patients treated with the telmisartan/HCTZ combination. The analysis of patients with moderate-tosevere hypertension also found that the BP-lowering efficacy of $\mathrm{T} 80 / \mathrm{H} 25$ was consistent across age, gender, and race subgroups. In contrast, the effect of valsartan was more variable. Furthermore, T80/H25 always showed larger BP reductions than V160/H25 across all subgroups, although these differences were not always significant. These results support the use of T80/H25 in patients with moderate-tosevere hypertension, regardless of age, gender, and race.

The magnitude of the differences in $\mathrm{BP}$ reductions observed in our analysis in the moderate-to-severe hypertensive patient population between treatment groups is 
TABLe 3: Adverse events with incidence $\geq 2 \%$.

\begin{tabular}{lccc}
\hline & T80/H25 $(n=337)$ & V160/H25 $(n=327)$ & Placebo $(n=87)$ \\
\hline Patients with any adverse event, $n(\%)$ & $94(27.9)$ & $73(22.3)$ & $37(42.5)$ \\
Upper respiratory tract infection, $n(\%)$ & $6(1.8)$ & $5(1.5)$ & $3(3.4)$ \\
Sinusitis, $n(\%)$ & $2(0.6)$ & $4(1.2)$ & $2(2.3)$ \\
Headache, $n(\%)$ & $8(2.4)$ & $7(2.1)$ & $4(4.6)$ \\
Dizziness, $n(\%)$ & $7(2.1)$ & $2(0.6)$ & $3(3.4)$ \\
US spelling-diarrhea $n(\%)$ & $5(1.5)$ & $1(0.3)$ & $2(3.4)$ \\
Dry mouth, $n(\%)$ & $1(0.3)$ & $2(0.6)$ & $2(2.3)$ \\
Vomiting, $n(\%)$ & - & $5(1.5)$ & $2(2.3)$ \\
Muscle spasm, $n(\%)$ & $3(0.9)$ & - & $5(5.7)$ \\
Hypertension, $n(\%)$ & - & $2(0.6)$ & $2(2.3)$ \\
Fatigue, $n(\%)$ & $6(1.8)$ & & \\
\hline
\end{tabular}

T80/H25: telmisartan $80 \mathrm{mg} /$ hydrochlorothiazide $25 \mathrm{mg}$; V160/H25: valsartan 80 mg/hydrochlorothiazide $25 \mathrm{mg}$.

clinically relevant. Mean reductions in BP were greater than 20/10 mm Hg for the SPC therapies, and the differences between T80/H25 and V160/H25 were also of clinical relevance. In a meta-analysis of one million adults from 61 prospective studies, the relationship between $\mathrm{BP}$ reduction and CV morbidity and mortality events supports that a reduction in SBP of just $2 \mathrm{~mm} \mathrm{Hg}$ would provide a $10 \%$ reduction in stroke mortality and 7\% lower mortality from US spelling-ischaemic heart disease and other vascular deaths [24]. In an earlier study that assessed observational data from two large population cohorts, a $2 \mathrm{~mm} \mathrm{Hg}$ reduction in DBP was shown to be associated with a $9 \%$ reduction in risk of coronary heart disease and a $15 \%$ reduction in stroke [25].

There is a good body of evidence showing that antihypertensive treatment involving ARBs can reduce CV morbidity and mortality in different types of at-risk hypertensive patients, such as those with additional CV risk factors $[8$, 9], patients with diabetes and documented target organ damage or a history of stroke and MI [13], and those with heart failure [10-12] and end-stage renal disease [7]. The clinical importance of using antihypertensive combinations that offer optimal BP reductions has also been highlighted in the findings of a number of large-scale intervention studies. For example, the Antihypertensive and Lipid-Lowering Treatment to Prevent Heart Attack Trial (ALLHAT) [26] and Valsartan Antihypertensive Long-term Use Evaluation (VALUE) trial [9] both demonstrated that when one pharmacological regimen induces greater reductions in BP than another, this may have important clinical implications in terms of reduction in CV and cerebrovascular morbidity, even during a treatment period of less than 1 year.

More recently, the Avoiding Cardiovascular Events through Combining Therapy in Patients Living with Systolic Hypertension (ACCOMPLISH) trial in patients at high risk for $\mathrm{CV}$ events, compared two treatment combinations that differed by just $1 \mathrm{~mm} \mathrm{Hg}$ in terms of mean SBP and DBP and reported that the more effective BP-lowering regimen was associated with a significant reduction in a primary composite endpoint of death from CV causes, nonfatal MI, nonfatal stroke, hospitalization for angina, resuscitation after sudden cardiac arrest, and coronary revascularizsation [6].

\section{Conclusion}

This pooled analysis confirmed that SPC therapy with T80/H25 o.d. reduced both SBP and DBP to a greater extent than V160/H25 in patients with moderate-to-severe hypertension, defined as SBP $\geq 160 \mathrm{~mm} \mathrm{Hg}$ at baseline. The superior antihypertensive efficacy of the telmisartan/HCTZ combination observed may reflect the longer half-life of telmisartan of $24 \mathrm{~h}$ compared with $7-9 \mathrm{~h}$ for valsartan. Analysis of pooled data therefore demonstrates that, in patients with moderate-to-severe hypertension, T80/H25 provides superior efficacy to V160/25, with a high rate of BP goal achievement and similar levels of tolerability. These findings support the use of long-acting ARBs such as telmisartan in combination with higher doses of thiazide diuretic $(25 \mathrm{mg})$ to provide improved BP control in the more severely hypertensive patient.

\section{Acknowledgments}

The authors were fully responsible for all content and editorial decisions, were involved at all stages of paper development, and have approved the final version. Editorial assistance, supported by Boehringer Ingelheim, was provided by Anne Jakobsen of PAREXEL.

\section{References}

[1] A. V. Chobanian, G. L. Bakris, H. R. Black et al., "The seventh report of the joint national committee on prevention, detection, evaluation, and treatment of high blood pressure: the JNC 7 Report," Journal of the American Medical Association, vol. 289, no. 19, pp. 2560-2572, 2003.

[2] G. Mancia, G. De Backer, A. Dominiczak et al., “2007 guidelines for the management of arterial hypertension: the task force for the management of arterial hypertension of the European Society of Hypertension (ESH) and of the European Society of Cardiology (ESC)," Journal of Hypertension, vol. 25, no. 6, pp. 1105-1187, 2007. 
[3] J. B. McGill and P. A. Reilly, "Telmisartan plus hydrochlorothiazide versus telmisartan or hydrochlorothiazide monotherapy in patients with mild to moderate hypertension: a multicenter, randomized, double-blind, placebo-controlled, parallel-group trial," Clinical Therapeutics, vol. 23, no. 6, pp. 833-850, 2001.

[4] M. C. Ruddy, "Angiotensin II receptor antagonists," in Hypertension: A Companion to Brenner and Rector's The Kidney, S. Oparil and M. A. Weber, Eds., pp. 621-637, WB Saunders Company, Philadelphia, Pa, USA, 2000.

[5] B. Dahlöf, P. S. Sever, N. R. Poulter et al., "Prevention of cardiovascular events with an antihypertensive regimen of amlodipine adding perindopril as required versus atenolol adding bendroflumethiazide as required, in the AngloScandinavian Cardiac Outcomes Trial-Blood Pressure Lowering Arm (ASCOT-BPLA): a multicentre randomised controlled trial," The Lancet, vol. 366, no. 9489, pp. 895-906, 2005.

[6] K. Jamerson, M. A. Weber, G. L. Bakris et al., "Benazepril plus amlodipine or hydrochlorothiazide for hypertension in highrisk patients," The New England Journal of Medicine, vol. 359, no. 23, pp. 2417-2428, 2008.

[7] G. Cice, A. Di Benedetto, S. D'Isa et al., "Effects of telmisartan added to angiotensin-converting enzyme inhibitors on mortality and morbidity in hemodialysis patients with chronic heart failure: a double-blind, placebo-controlled trial," Journal of the American College of Cardiology, vol. 56, no. 21, pp. 17011708, 2010.

[8] B. Dahlöf, R. B. Devereux, S. E. Kjeldsen et al., "Cardiovascular morbidity and mortality in the Losartan Intervention For Endpoint reduction in hypertension study (LIFE): a randomised trial against atenolol," The Lancet, vol. 359, no. 9311, pp. 995-1003, 2002.

[9] S. Julius, S. E. Kjeldsen, M. Weber et al., "Outcomes in hypertensive patients at high cardiovascular risk treated with regimens based on valsartan or amlodipine: the VALUE randomised trial," The Lancet, vol. 363, no. 9426, pp. 2022 2031, 2004.

[10] A. P. Maggioni, R. Latini, P. E. Carson et al., "Valsartan reduces the incidence of atrial fibrillation in patients with heart failure: results from the Valsartan Heart Failure Trial (Val-HeFT)," American Heart Journal, vol. 149, no. 3, pp. 548-557, 2005.

[11] J. McMurray, S. Solomon, K. Pieper et al., "The effect of valsartan, captopril, or both on atherosclerotic events after acute myocardial infarction: an analysis of the valsartan in acute myocardial infarction trial (VALIANT)," Journal of the American College of Cardiology, vol. 47, no. 4, pp. 726-733, 2006.

[12] M. A. Pfeffer, K. Swedberg, C. B. Granger et al., "Effects of candesartan on mortality and morbidity in patients with chronic heart failure: the CHARM-overall programme," The Lancet, vol. 362, no. 9386, pp. 759-766, 2003.

[13] S. Yusuf, K. K. Teo, J. Pogue et al., "Telmisartan, ramipril, or both in patients at high risk for vascular events," The New England Journal of Medicine, vol. 358, no. 15, pp. 1547-1559, 2008.

[14] M. Moser, "Update on the management of hypertension: recent clinical trials and the JNC 7," Journal of Clinical Hypertension, vol. 6, no. 10, supplement 2, pp. 4-13, 2004.

[15] W. B. White, H. A. Punzi, D. Murwin, S. E. Koval, G. Davidai, and J. M. Neutel, "Effects of the angiotensin II receptor blockers telmisartan vs valsartan in combination with hydrochlorothiazide $25 \mathrm{mg}$ once daily for the treatment of hypertension," Journal of Clinical Hypertension, vol. 8, no. 9, pp. 626-633, 2006.
[16] W. B. White, D. Murwin, S. G. Chrysant, S. E. Koval, G. Davidai, and R. Guthrie, "Effects of the angiotensin II receptor blockers telmisartan versus valsartan in combination with hydrochlorothiazide: a large, confirmatory trial," Blood Pressure Monitoring, vol. 13, no. 1, pp. 21-27, 2008.

[17] W. B. White, G. Davidai, and H. Schumacher, "Impact of angiotensin receptor blockade in combination with hydrochlorothiazide $25 \mathrm{mg}$ in 2121 patients with stage 1-2 hypertension," Journal of Human Hypertension, vol. 23, no. 12, pp. 817-825, 2009.

[18] J. R. Benz, H. R. Black, A. Graff, A. Reed, S. Fitzsimmons, and Y. Shi, "Valsartan and hydrochlorothiazide in patients with essential hypertension. A multiple dose, double-blind, placebo controlled trial comparing combination therapy with monotherapy," Journal of Human Hypertension, vol. 12, no. 12, pp. 861-866, 1998.

[19] P. Trenkwalder, H. J. Ulmer, G. Weidinger, and R. Handrock, "Efficacy and safety of valsartan 160mg/hydrochlorothiazide $25 \mathrm{mg}$ combination in patients with hypertension not adequately controlled by valsartan $160 \mathrm{mg} /$ hydrochlorothiazide $12.5 \mathrm{mg}$, Clinical Drug Investigation, vol. 24, no. 10, pp. 593$602,2004$.

[20] Y. Lacourcière, J. M. Krzesinski, W. B. White, G. Davidai, and H. Schumacher, "Sustained antihypertensive activity of telmisartan compared with valsartan," Blood Pressure Monitoring, vol. 9, no. 4, pp. 203-210, 2004.

[21] W. B. White, Y. Lacourciere, and G. Davidai, "Effects of the angiotensin II receptor blockers telmisartan versus valsartan on the circadian variation of blood pressure: impact on the early morning period," American Journal of Hypertension, vol. 17, no. 4, pp. 347-353, 2004.

[22] M. Burnier, "Telmisartan: a different angiotensin II receptor blocker protecting a different population?" The Journal of International Medical Research, vol. 37, no. 6, pp. 1662-1679, 2009.

[23] F. V. Costa, "Telmisartan: standing out in a crowded contest?" High Blood Pressure and Cardiovascular Prevention, vol. 13, no. 3, pp. 85-94, 2006.

[24] S. Lewington, R. Clarke, N. Qizilbash, R. Peto, and R. Collins, "Age-specific relevance of usual blood pressure to vascular mortality: a meta-analysis of individual data for one million adults in 61 prospective studies," The Lancet, vol. 360, no. 9349, pp. 1903-1913, 2002.

[25] N. R. Cook, J. Cohen, P. R. Hebert, J. O. Taylor, and C. $\mathrm{H}$. Hennekens, "Implications of small reductions in diastolic blood pressure for primary prevention," Archives of Internal Medicine, vol. 155, no. 7, pp. 701-709, 1995.

[26] "Major outcomes in high-risk hypertensive patients randomized to angiotensin-converting enzyme inhibitor or calcium channel blocker vs diuretic: the Antihypertensive and LipidLowering Treatment to Prevent Heart Attack Trial (ALLHAT)," Journal of the American Medical Association, vol. 288, no. 23, pp. 2981-2997, 2002. 


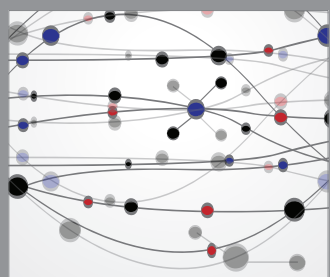

The Scientific World Journal
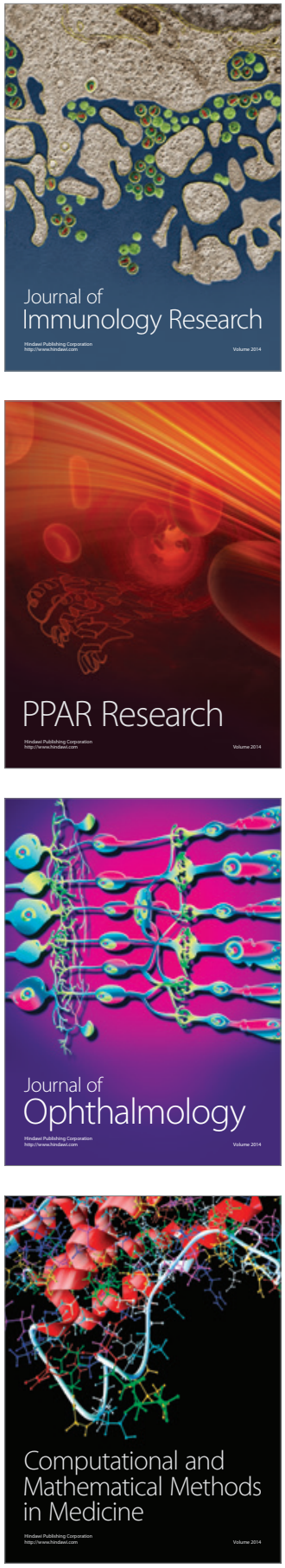

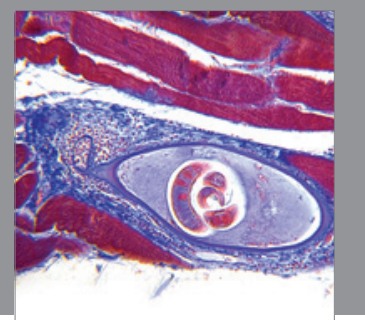

Gastroenterology

Research and Practice
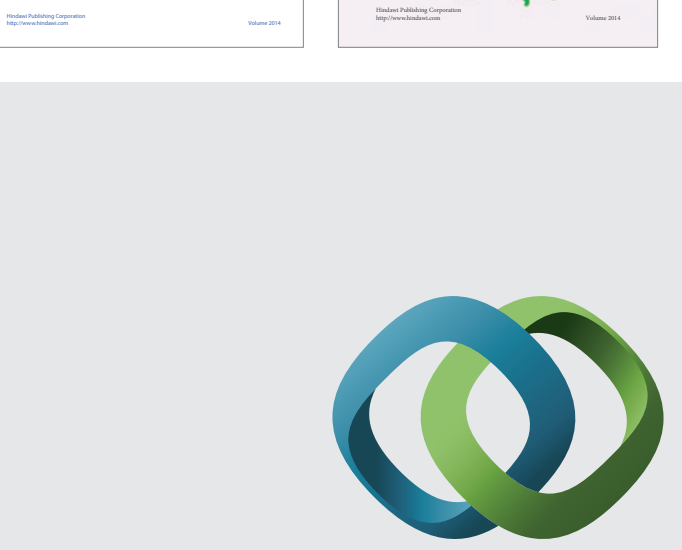

\section{Hindawi}

Submit your manuscripts at

http://www.hindawi.com
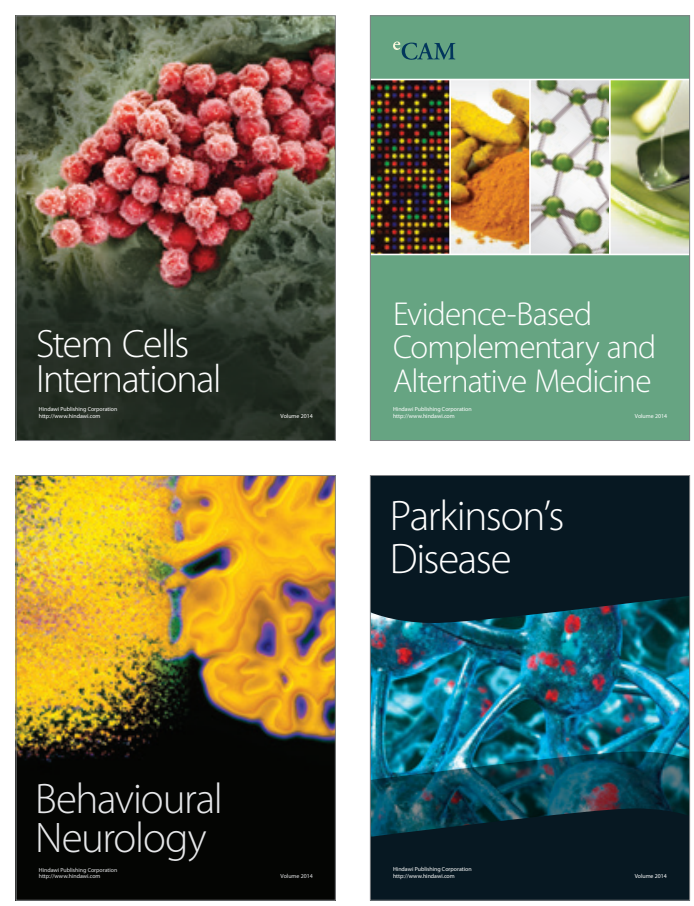

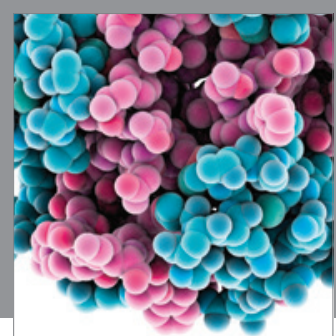

Journal of
Diabetes Research

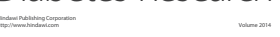

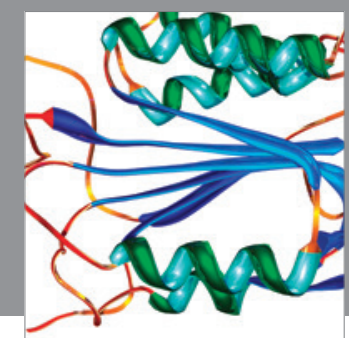

Disease Markers
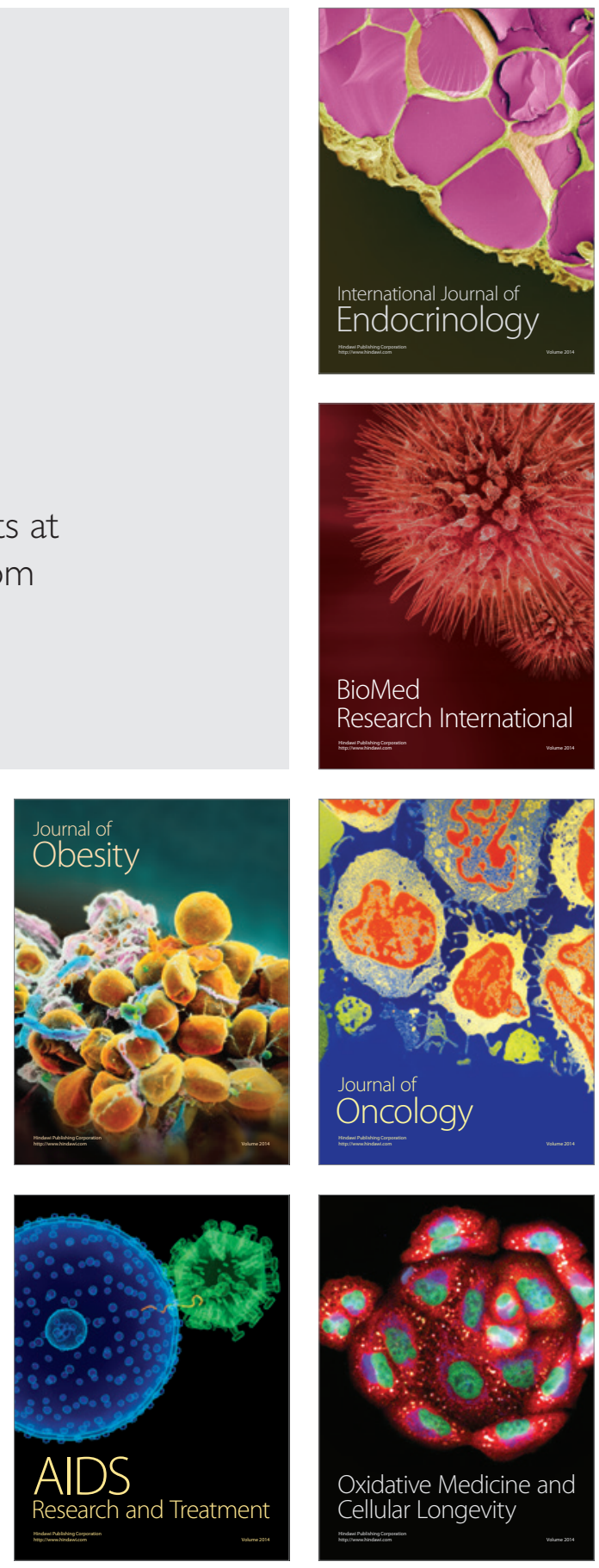